\title{
SEMINÁRIO NACIONAL DE ENFERMAGEM EM SAÚDE MENTAL - RELATÓRIO FINAL
}

\author{
Maguida Costa Stefanelli* \\ Marli Alves Rolim* \\ Sônia Barros* \\ Marina Borges Teixeira* \\ Hideko Takeuchi Forcella* \\ Ilza Marlene Kuae Fukuda* \\ Evalda Cançado Arantes*
}

STEFANELLI, M.C. et al. Seminário nacional de enfermagem em saúde mental:-relatorio final.

Rev.Esc.Enf.USP, v.28, n.3, p.337-41, dez. 1994.

O evento foi organizado por membros do $8^{\circ}$ Centro Colaborador da OMS para Pesquisa e Treinamento em Saúde Mental, na Escola de Enfermagem da USP, nos dias 28 e 29 de março de 1994.

Participaram do seminário 55 enfermeiros e docentes da área de Enfermagem Psiquiátrica e de Saúde Mental, com representação da maioria dos Estados do Brasil.

Destacaram-se, na sessāo de abertura, as presenças da Coordenadora de Saúde Mental do Ministério da Saúde - Eliane Seidl, do Coordenador Geral do Brasil, dos Centros Colaboradores da OMS, na época Valentin Gentil Filho, e de representantes dos Secretários de Saúde do Estado e do Município de São Paulo.

A finalidade do evento foi verificar quais aspectos da Reforma da Assistência Psiquiátrica estavam sendo contemplados nos currículos de graduação das Escolas de Enfermagem, bem como determinar diretrizes básicas no ensino para atender as recomendações da mesma.

Após a abertura da sessão pela Sra. Diretora da Escola de Enfermagem, Tamara Iwanow Cianciarullo, tomou a palavra a coordenadora do referido Centro e do evento, Maguida Costa Stefanelli, apresentando o $8^{2}$ Centro Colaborador da OMS, sediado na EEUSP. Algumas pessoas que compunham a mesa da sessão de abertura fizeram uso da palavra, entre elas Maria Alice Tsunechiro, chefe do Departamento de Enfermagem Materno-Infantil e Psi-

Enfermeiras. Membros do Centro Colaborador da OMS para Pesquisa e Treinamento em Saude Mental. Departamento de Enfermagem Materno Infantil e Psiquiatrica da Escola de Enfermagem da Universidade de Săo Paulo. 
quiátrica da EEUSP. Posteriormente, Eliane Seidl deu início à sua palestra "Assistência psiquiátrica no Brasil".

No período da tarde (14h), Maguida Costa Stefanelli apresentou relatório preliminar referente à pesquisa desenvolvida pelo $8^{2}$ Centro, tendo como base os dados sobre o ensino de saúde mental no Brasil, coletados junto às 40 escolas que responderam ao questionário enviado pelo referido Centro.

Aproximadamente às $15 \mathrm{~h}$ os participantes foram distribuídos em 4 grupos, tendo como temas para discussão e documentos para embasá-la, o que segue:

\section{Tema: Legislação}

Documentos:

- Projeto de lei "Roberto Gouveia";

- Projeto de lei "Paulo Delgado";

- Lei de Reforma Psiquiátrica do Rio Grande do Sul;

- Encontro de Parlamentares Estaduais sobre Legislação Psiquiátrica no Brasil.

Tema: Diretrizes do Ministério da Saúde

- Portarias: 224, 88, 408, 189, 407;

- Elementos para uma análise de assistência de saúde mental no Brasil.

Tema: Currículo

Formação do trabalhador em saúde mental.

Documentos:

- Currículo mínimo vigente;

- Proposta para currículo mínimo;

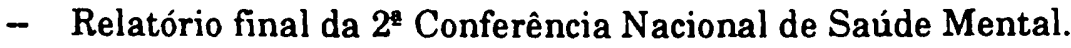

Tema: Marco Conceitual

Documentos:

- Relatório final da $2^{\mathrm{a}}$ Conferência Nacional de Saúde Mental;

- Organização das Naçōes Unidas: proteção de pessoas com enfermidade mental e a melhoria da assistência à Saúde Mental;

- Reestruturação da assistência psiquiátrica: bases conceituais e caminhos para sua implementação.

No dia 29/03/94, pela manhã, alguns grupos ainda se reuniram para finalizar os seus relatórios e, logo após, houve apresentação dos mesmos pelos respectivos representantes dos grupos.

Posteriormente, reuniram-se os representantes dos grupos com os membros do Centro Colaborador para a elaboração do relatório final do evento e para os demais participantes o período ficou livre para diversas atividades.

No período da tarde, sob coordenação de Sônia Barros, houve sessão plenária para discussão e aprovação do relatório final contendo algumas recomendações que se configuram como algumas diretrizes norteadoras do ensino de Enfermagem Psiquiátrica e em Saúde Mental. 
Vale esclarecer que o relatório (anexo I), sugerido para discussão em grupo, foi considerado extenso demais para que todos seus elementos fossem contemplados em apenas dois dias de Seminário.

Portanto, o relatório final delineou-se da forma como segue.

"No entender do grupo, há pouco subsídios para se avaliar o item do roteiro Aspectos da Reforma da Assistência Psiquiátrica que estão sendo contemplados nos currículos de graduação das escolas respondentes, uma vez que o formulário não inclui temáticas sobre esse assunto entre as alternativas assinaladas.

Com as informações a que tivemos acesso, pudemos inferir que a Reforma Psiquiátrica está, de uma maneira geral, sendo minimamente contemplada, uma vez que o relatório preliminar da pesquisa junto às escolas de enfermagem contempla a inclusão de algumas experiências extra-hospitalares. Isso, no entanto, não nos fornece dados de como estão sendo ministrados os conteúdos desse ensino, pois a mudança de local da prática de ensino de enfermagem, por si só, não garante ou não revela mudança de mentalidade da assistência. O relatório nos mostra, no entanto, a tendência do ensino de Enfermagem Psiquiátrica centrado no hospital, contemplando o modelo hospitalocêntrico.

Vislumbra-se, ainda, a existência de um movimento de transformação devido à inclusão de algumas experiências isoladas em que o ensino está sendo ministrado em serviços extra-hospitalares, embora o instrumento de coleta de dados da pesquisa não tenha incluído dados a respeito de como estão sendo ministrados os conteúdos desse ensino.

Ressalta-se que o grupo lembra que a aderência à Reforma Psiquiátrica não depende exclusivamente do local de prática do ensino.

Dentre os representantes de escolas presentes no grupo, foi levantada também a dificuldade prática em instrumentalizar o ensino em serviço alternativo à hospitalização, considerando-se que deve haver adequação entre o número de docentes e o número de alunos, de acordo com as condições oferecidas pelos serviços.

Julga-se que haja dificuldade por parte dos docentes em incorporar os princípios dessa Reforma que representa a aquisição de novos conhecimentos teóricos e práticos para o desenvolvimento das atividades de Enfermagem Psiquiátrica e em Saúde Mental que exigem posturas mais flexíveis e participativas, visando a interdisciplinaridade. E lembrado que o ensino está excessivamente centrado no modelo médico tradicional.

Parece haver pouca inserção dos docentes das Escolas de Enfermagem em programas assistenciais que promovam as mudanças preconizadas e em oferecer um saber que realmente as torne viáveis.

Considera-se que as Escolas de Enfermagem, de modo geral, neste momento, ainda não estão produzindo conhecimento suficiente para subsidiar as novas práticas exigidas pela Reforma Psiquiátrica que já estão sendo implementadas em alguns serviços assistenciais.

Embasados em tais ponderações, recomendamos: 
- que as escolas definam seus marcos conceituais que fundamentam seus programas de ensino em Enfermagem Psiquiátrica e em Saúde Mental. A sugestão é de que a referência seja os marcos conceituais contidos no Relatório Final da II Conferência Nacional de Saúde Mental que define a atenção integral e a cidadania como eixos norteadores da assistência;

- que seja inserida a discussão da Reforma Psiquiátrica, no ensino de Enfermagem Psiquiátrica e em Saúde Mental, inclusive da legislação que a regulamenta, recuperando o debate sobre a loucura em sua historicidade a partir de uma análise crítica.

- que se promova a discussão dos vários modelos teóricos que embasam o conteúdo do ensino;

- cursos de especialização em Saúde Mental com participação multiprofissional;

- que as Escolas estejam envolvidas em cursos de treinamento e de reciclagem do pessoal de serviços;

- que o $8^{2}$ Centro Colaborador da OMS no Brasil promova novo encontro para a discussão das temáticas referidas anteriormente, garantindo espaço de intercâmbio entre os participantes;

- que a interdisciplinaridade seja abordada ou ocorra no nível da unidade de ensino, com outras unidades da Universidade e com os profissionais que trabalham no serviço;

- que o ensino contemple a psicopatologia, porém, que fique garantida que a abordagem esteja centrada na pessoa em sua existência;

- incluir conhecimentos epidemiológicos que contemplem a Reforma da Assistência Psiquiátrica;

- que o ensino das ciências sociais preceda a disciplina Enfermagem Psiquiátrica e em Saúde Mental, oferecendo subsídios necessários e de forma articulada entre os docentes;

- enfatizar o relacionamento interpessoal tanto no que se refere ao ensino quanto à assistência no processo saúde e doença mental, considerando a pessoa no seu contexto;

- o ensino dos vários tipos de terapêuticas disponiveis na prática e na literatura;

- que se promova a discussão dos vários modelos assistenciais nos programas de disciplinas, enfatizando o indivíduo na sua integralidade no processo saúde/doença mental, contextualizando o indivíduo como ser histórico-social;

- que os representantes dos vários Estados aqui presentes envidem esforços para promover discussão sobre a Reforma Psiquiátrica em nivel local;

- que haja integração de docentes e enfermeiros assistenciais para que esse saber referente à Reforma possa ser compartilhado e, também, subsidiar de forma efetiva a implantação das tecnologias adequadas à situação vigente". 


\section{SEMINÁRIO NACIONAL DE ENFERMAGEM EM SAÚDE MENTAL}

\section{ROTEIRO PARA DISCUSSÃO DO GRUPO}

1. Leitura do documento produzido.

2. Discussão à luz de documentos que tratam da reforma de assistência psiquiátrica e do ensino de saúde mental. Cada grupo fará análise tendo por base 2 a 3 dos documentos.

3. Após a leitura dos documentos verificar que aspectos da Reforma Psiquiátrica estão sendo contemplados nos currículos de graduạ̧ão em enfermagem das escolas respondentes.

4. Detectar os aspectos que nāo estāo sendo atendidos.

5. Determinar as ações de enfermagem necessárias para atender as recomendações dos documentos.

6. A seguir, arrole $n s$ conteúdos que devem ser ensinados para melhor instrumentalizar $n$ enfermeiro para $\cap$ desempenho das açōes citadas.

7. Considerando a realidade brasileira, recursos humanos e materiais existentes e as possibilidades para o ensino de Enfermagem em Saúde Mental, entendendo que esta disciplina engloba o processo saúde-doença mental, dê sugestões para a implementaçāo das açōes definidas como necessárias, no menor espaço de tempo possível, destacando:

- carga horária mínima;

- proporção professor/alunos;

- campo de estágio;

- preparo do professor;

- preparo do campo;

- como e quando ensinar as açōes no curso de graduação de enfermagem. 